\title{
Cost-effectiveness of postoperative rehabilitation after surgery for lumbar disc herniation: an analysis based on a randomized controlled trial
}

\author{
Rune T. Paulsen, MD, ${ }^{1}$ Jan Sørensen, MSc, ${ }^{2}$ Leah Y. Carreon, MD, MSc, ${ }^{1}$ and \\ Mikkel Ø. Andersen, MD ${ }^{1}$
}

1Spine Surgery and Research, Spine Centre of Southern Denmark, Lillebaelt Hospital, Middelfart, and the Institute of Regional Health Research, University of Southern Denmark, Odense, Denmark; and ${ }^{2}$ Healthcare Outcome Research Centre, Royal College of Surgeons in Ireland, Dublin, Ireland, and the Danish Centre for Health Economics, University of Southern Denmark, Odense, Denmark

OBJECTIVE The aim of this study was to examine whether routine referral to municipal postoperative rehabilitation is cost-effective in comparison to no referral after surgery for lumbar disc herniation (LDH).

METHODS One hundred forty-six patients scheduled for primary discectomy due to LDH were included. This secondary analysis, based on data from a previous randomized controlled trial, compared costs and quality-adjusted life years (QALYs) between two groups of patients recovering from LDH surgery: one group of patients received a referral for municipal physical rehabilitation (REHAB) and the other group was sent home without a referral to any postoperative rehabilitation (HOME). Primary outcomes were QALYs calculated from the EQ-5D utility score, societal costs, and incremental cost-effectiveness ratios (ICERs). The main cost-effectiveness analysis used intention-to-treat data, whereas sensitivity analyses included as-treated data. Questionnaires were collected after 1, 3, 6, 12, and 24 months postoperatively.

RESULTS The main cost-effectiveness analysis showed a small, insignificant incremental QALY of 0.021 and an incremental cost of $€ 211.8$ for the REHAB group compared to the HOME group, resulting in an ICER of $€ 10,085$. In the astreated sensitivity analysis, the REHAB group had poorer outcomes and higher costs compared to the HOME group.

CONCLUSIONS Routine referral to municipal physical rehabilitation in patients recovering from LDH surgery was not cost-effective compared to no referral.

Clinical trial registration no.: NCT03505918 (clinicaltrials.gov)

https://thejns.org/doi/abs/10.3171/2019.11.SPINE191003

KEYWORDS lumbar disc herniation; spine surgery; discectomy; rehabilitation; physical training; recovery; supervised physical exercise; cost-effectiveness; economic evaluation

$\mathrm{L}$ UMBAR disc herniation (LDH) is a common spinal disease with symptoms that include low-back pain and radicular pain in the lower extremities. ${ }^{13,18}$ The natural course of LDH is favorable, with spontaneous improvement during the initial 6-12 weeks postinjury with nonsurgical care. ${ }^{8}$ However, a small percentage of LDH patients require surgical discectomy, a widely accepted procedure in the treatment of LDH. ${ }^{4}$ In Denmark, the number of lumbar discectomies has remained stable dur- ing the last 5 years, with approximately 2000 procedures per year, making it the second most commonly performed spinal surgical procedure in the country. ${ }^{1}$

In Denmark, LDH patients are typically referred for rehabilitation starting 4-6 weeks postoperatively, although the evidence for beneficial effects is sparse and conflicting. ${ }^{12}$ The latest Cochrane review ${ }^{12}$ called for new studies evaluating the cost-effectiveness of postoperative rehabilitation since only a few previous studies investigated this

ABBREVIATIONS ICER = incremental cost-effectiveness ratio; $\mathrm{LDH}=$ lumbar disc herniation; $\mathrm{MCID}=$ minimum clinically important difference; $\mathrm{ODI}=\mathrm{Oswestry}$ Disability Index; QALY = quality-adjusted life year; RTW = return to work.

SUBMITTED August 30, 2019. ACCEPTED November 5, 2019.

INCLUDE WHEN CITING Published online January 17, 2020; DOI: 10.3171/2019.11.SPINE191003. 
for LDH patients. ${ }^{11,13}$ Previous studies found no evidence to indicate that postoperative rehabilitation is cost-effective, and given that most Danish LDH patients are routinely referred for postoperative rehabilitation, it is relevant to explore the cost-effectiveness of rehabilitation strategies from a Danish societal perspective.

The aim of this study was to investigate whether routine referral for municipal physical rehabilitation is costeffective in comparison with no referral after surgery for $\mathrm{LDH}$.

\section{Methods}

This is a secondary analysis based on data from a single-center randomized controlled trial with 1:1 parallel group allocation. The data collection was designed and conducted as a single-blind trial comparing postoperative outcomes for patients referred to municipal physical rehabilitation (REHAB) to those of patients who were sent home without a referral to any postoperative rehabilitation (HOME) after surgery for LDH. The study is reported in accordance with the CONSORT guidelines ${ }^{10}$ and study details have been published (clinical trial registration no.: NCT03505918; clinicaltrials.gov). Relevant approvals for conducting the study were obtained from the regional ethics committee. Elements from the Methods section have been published previously. ${ }^{15}$

Briefly, eligible patients were scheduled for primary discectomy at the Spine Centre at Middelfart Hospital between September 2015 and January 2017. Inclusion criteria were age between 18 and 65 years and MRI-confirmed single-level symptomatic LDH with indications for discectomy. Exclusion criteria were previous spine surgery, psychiatric disorder, malignant disease, major surgical procedure(s) within 12 months prior to inclusion, and chronic nonspecific pain disorders (fibromyalgia, whiplash, etc.).

All patients received our standard operative treatment of either open discectomy or microdiscectomy and were hospitalized for 1-2 days. At discharge, all patients attended an informational meeting with the department's physiotherapists and were instructed to perform standard home exercises for the first 4 weeks after discharge as part of their standard care. Additionally, all patients received a standard informational booklet about disc herniation and the common recommendations after surgery. All patients were scheduled for an outpatient clinic visit with the department's physiotherapist 1 month after surgery as part of standard care.

Standard policy is to make individual rehabilitation plans for all patients, along with referral to municipal rehabilitation starting 4-6 weeks postoperatively. The RE$\mathrm{HAB}$ group followed this standard procedure with rehabilitation at the municipal facility. REHAB patients were hereafter invited to an individual startup meeting with the municipal physiotherapists, and the rehabilitation course was planned by joint decision with the patients and the physiotherapists. However, a typical municipal rehabilitation course consists of either individual 1:1 sessions or group sessions with physiotherapists 1-2 times weekly for approximately $8-10$ weeks. Further information on the provided rehabilitation is presented in the Results section. The HOME group patients were seen on a 1-month outpatient basis and then released without any additional scheduled clinic visits or referrals for postoperative treatments.

\section{Randomization}

This study used 1:1 parallel block randomization with blocks of 6. Randomization occurred on the day of surgery before the surgical procedure and was performed by a physiotherapist. Patients had to select among 6 sealed envelopes for randomization. Only the physiotherapist and patients had knowledge of the assigned group. The primary investigator and surgeon remained blinded to patients' allocation during the course of this study.

\section{Sample Size}

Sample size calculation was done for the primary analysis of this study using the Oswestry Disability Index (ODI) as the primary outcome measure. ${ }^{3}$ We used an estimated mean value for the control group of 24, a standard deviation of 16 , and a delta value between groups of 8 . With a power of $80 \%$ and an alpha of $5 \%$, we needed at least 64 patients in each group. The sample size was further increased by $15 \%$ to account for dropouts and death during the study. Thus, we needed to enroll 74 subjects in each arm and 148 in total.

\section{Data Collection}

Baseline characteristics were collected preoperatively, and outcome data were collected through postal questionnaires after 1, 3, 6, 12, and 24 months. Additionally, patients were contacted by phone between 1 and 2 years after surgery to confirm dates of return to work (RTW) and obtain data about the rehabilitation phase.

The 1-month health status measures were used as a baseline for the outcome assessment (quality-adjusted life year [QALY] calculations) as rehabilitation started at this point and to exclude the effects of the surgical procedure as much as possible.

\section{Utility Scores}

To evaluate the health-related quality of life, we used the Danish EQ-5D questionnaire, which evaluates 5 health dimensions on a 3-point scale. The Danish algorithm ${ }^{17}$ was used to create a utility score ranging from 0 to 1 , where 1 indicates utility of perfect health and 0 indicates death. Negative scores may appear and indicate health states worse than death. The EQ-5D utility scores weighted with time intervals were used to estimate the QALYs 12 months after baseline. The minimum clinically important difference (MCID) for this utility is considered to be approximately $0.17^{6}$ in patients with degenerative disc disease.

The ODI, used as a supplementary functional measure, has scores ranging from 0 to 100 , with 100 indicating maximum disability and 0 no disability. The MCID for this instrument is 12 points. $^{2}$

To investigate the duration of postoperative sick leave for the cost evaluation, all patients were asked for the date of RTW on the 1-year follow-up questionnaire. All patients were additionally contacted by phone to confirm the 
sick leave period registered in the 1-year questionnaire. Patients with missing RTW data were asked for the date during the phone interview. The sick leave period in days was counted between the date of surgery and the date of RTW. However, some patients did not report the exact date of RTW but instead estimated the weeks of absenteeism. In these cases, the weeks were converted to days. Twelve patients were unemployed or retired and were not included in the sick leave calculations.

\section{Cost Measures}

Costs were estimated from a societal perspective and included costs related to the municipal rehabilitation and use of primary healthcare services 3 months after surgery. In one of the sensitivity analyses, absence from work was included as an indirect cost.

Healthcare Costs. The hourly cost of municipal rehabilitation included the cost of physiotherapists and the facilities needed to provide rehabilitation. It was assumed that an individual rehabilitation session with a physiotherapist lasted 30 minutes and group rehabilitation sessions with 7 patients lasted 1 hour with one physiotherapist. It was further assumed that the ratio of training, preparation, and documentation was approximately 50:50, meaning that for each 60 minutes of training the physiotherapist used an additional 60 minutes for preparation and documentation.

Patients registered the number of visits to the general practitioner during the first 12 weeks postoperatively. After 12 weeks, it was assumed that there were no differences in visits to the general practitioner between the two groups. The cost of contacts with general practitioners was obtained from current fee structures according to the Danish Medical Association.?

The annual salary of a physiotherapist was obtained from the Danish Physiotherapist Association. We assumed that spine rehabilitation was provided by physiotherapists with at least 4 years of experience. The salary was assumed at $€ 47,000 /$ year and the work time of a full-time physiotherapist was assumed at 1620 hours/year (i.e., 44 weeks at 37 hours/week). We further estimated that approximately $10 \%$ of the working time was used for sick leave, courses, and education.

The cost of equipment and buildings was estimated by assuming that the cost of a new-build facility is $€ 3350$ / $\mathrm{m}^{2}$ and that the training facility was at least $150 \mathrm{~m}^{2}$. This building cost was annualized using a $4 \%$ discount rate, as recommended by the Danish Ministry of Finance, with a 20-year depreciation period. This resulted in an annual cost estimated at $€ 37,000$ per year (i.e., $€ 0.5 \mathrm{M} / 13.59$ [annuity $4 \%$ over 20 years]). Assuming these facilities were used 2080 hours/year (i.e., 52 weeks $\times 5$ days/week $\times 8$ hours/day) and 10 patients used the facilities at the same time, the hourly cost per patient was estimated at $€ 1.8$ per hour. This cost was added to the additional costs per patient.

Indirect Societal Costs. The cost of absenteeism was included in the sensitivity analyses and was based on the average income for both Danish men and women between 30 and 49 years of age. Data were obtained from Statistics Denmark (www.dst.dk), and the average annual income in
2017 was $€ 54,517$ within this group. These costs were divided by 220 working days (i.e., 44 weeks at 5 days/week) to quantify the societal cost per absent workday of $€ 216$.

\section{Cost-Effectiveness Analyses}

The incremental cost-effectiveness ratio (ICER) is a commonly used measure in cost-effectiveness analyses and is calculated through division of the difference in costs and the difference in effect between two groups. The ICER thereby represents the cost per QALY gained.

By evaluating ICERs, it is possible to determine if the ICER is below a set threshold value for cost-effectiveness. In Denmark, there is no officially accepted threshold value, so decisions are made individually for each treatment. However, the National Institute for Health and Care Excellence in the United Kingdom applies a threshold value between $£ 22,000$ and $£ 33,000$ per QALY. ${ }^{9}$

\section{Statistical Analysis}

The primary analyses were conducted using intentionto-treat data with patients in their original groups without accounting for patients crossing groups.

Preoperative baseline characteristics were compared between the groups and analyzed with the chi-square test and unpaired t-tests and presented with numbers, frequencies, means, and $\mathrm{p}$ values.

EQ-5D and ODI scores are presented as group means, standard deviations, and number of valid responses before imputation. Potential patterns in missing EQ-5D data were explored between groups and baseline characteristics using graphical inspection and logistic regression. No systematic pattern could be identified. Missing utility scores were imputed as the interpolated average calculated from the earlier and later values if these were available and if the patient had not been lost to follow-up at the given time. For the remaining missing values, we performed a regression analysis adjusted for sex and age to predict missing QALY values before the production of graphs. ICERs were calculated and bootstrapped with 1000 replications. The bootstrapped ICER is presented graphically with cost-effectiveness acceptability curves where a range of threshold values is used to visualize the probability that the REHAB intervention is cost-effective. Five different sensitivity analyses were conducted to test the robustness of the ICER: United Kingdom-weighted EQ-5D index values, inclusion of 24-month EQ-5D values, inclusion of costs related to absenteeism, as-treated grouping, and perprotocol grouping. All analyses were conducted in Stata version 15.1 (StataCorp LLC), with a p value threshold of 0.05 to indicate statistical significance.

\section{Results}

Between September 2015 and January 2017, 146 eligible patients were enrolled and randomized (Fig. 1): 73 to the REHAB group and 73 to the HOME group. Follow-up rates were $78 \%$ after both 1 and 2 years. Baseline characteristics are presented in Table 1.

The municipal rehabilitation program consisted of individual 1:1 physiotherapy in $45.3 \%$ of the cases, group sessions in $50.9 \%$, and home training with follow-ups in 
Assessed for eligibility $n=192$

Declined to participate $n=30$

Accepted inclusion $n=162$

Cancelled surgery $n=8$, withdrew before surgery $n=8$

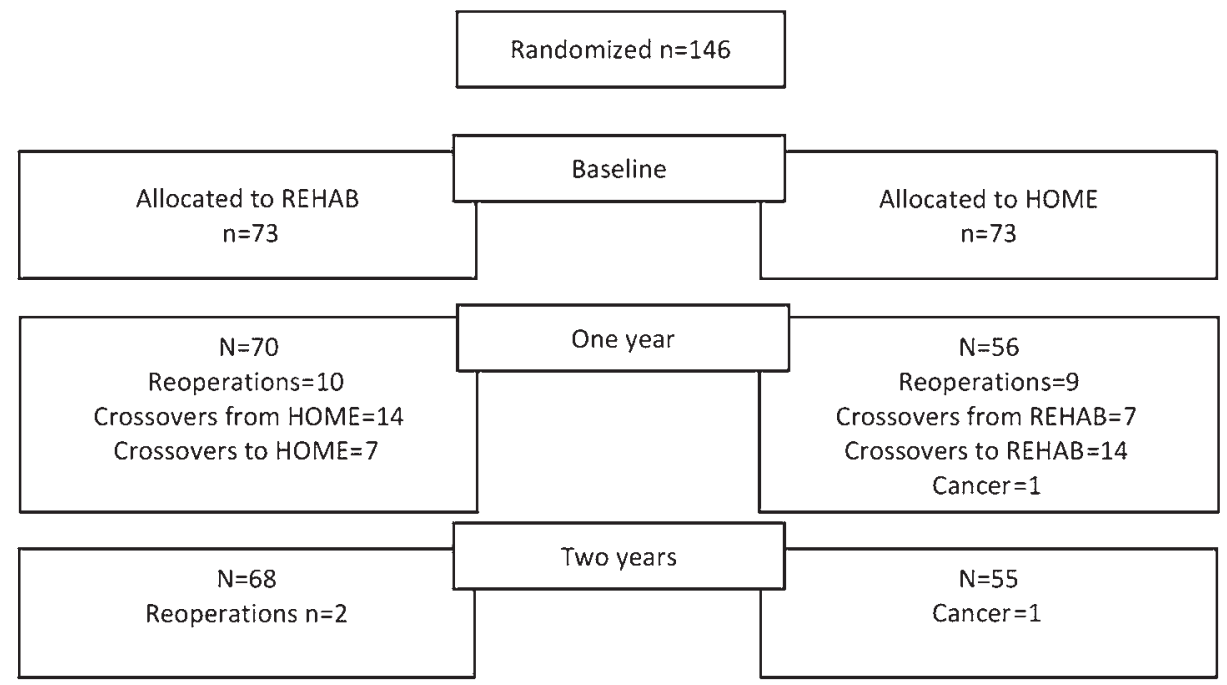

FIG. 1. Flowchart explaining the grouping of patients during the study period.

$3.8 \%$. Patients typically had $1-2$ weekly visits at the municipal center (93.6\%) for 6-12 weeks (62.3\%). One patient in both groups had visits to the general practitioner during the initial 3 months for reasons related to their back diagnosis. Unit costs related to the rehabilitation course are presented in Table 2.

\section{TABLE 1. Baseline characteristics}

\begin{tabular}{lcll}
\hline \multicolumn{1}{c}{ Characteristic } & REHAB & HOME & p Value \\
\hline No. of patients & $73(50.0 \%)$ & $73(50.0 \%)$ & \\
\hline Mean age, yrs (SD) & $42.9(8.9)$ & $42.8(11.8)$ & 0.981 \\
\hline Males & $63.0 \%$ & $63.0 \%$ & 1.000 \\
\hline Smokers & $34.2 \%$ & $39.7 \%$ & 0.453 \\
\hline Mean BMl, kg/m ${ }^{2}(\mathrm{SD})$ & $26.2(4.0)$ & $26.1(3.9)$ & 0.925 \\
\hline Preop job status & & & 0.698 \\
\hline Employed & $90.4 \%$ & $93.2 \%$ & \\
\hline Unemployed & $4.1 \%$ & $2.7 \%$ & \\
\hline Pension & $5.5 \%$ & $4.1 \%$ & \\
\hline Duration of leg pain & & & 0.490 \\
\hline No leg pain & $1.4 \%$ & $0 \%$ & \\
\hline$<3$ mos & $36.9 \%$ & $28.8 \%$ & \\
\hline $3-12$ mos & $45.2 \%$ & $46.6 \%$ & \\
\hline $1-2$ yrs & $13.7 \%$ & $17.8 \%$ & \\
\hline$>2$ yrs & $2.7 \%$ & $6.8 \%$ & \\
\hline
\end{tabular}

EQ-5D scores improved significantly in both groups during follow-up. The improvements between the groups were comparable over time and showed insignificant and clinically unimportant improvements in the REHAB group. ODI scores in both groups also showed small improvements during follow-up and insignificant and clinically unimportant improvements in the REHAB group. The greatest improvements in both EQ-5D and ODI scores were observed from preoperative to 1-month baseline: the mean EQ-5D score improvement was 0.24 in the REHAB group and 0.26 in the HOME group. Table 3 provides a

TABLE 2. Unit costs

\begin{tabular}{|c|c|}
\hline Cost Category & $\begin{array}{c}\text { Unit Cost } \\
\text { (2018 euros) }\end{array}$ \\
\hline \multicolumn{2}{|l|}{ Direct healthcare costs } \\
\hline \multicolumn{2}{|l|}{ Primary care costs } \\
\hline Individual physiotherapy, per treatment session & 32.5 \\
\hline Group physiotherapy, per session & 10.8 \\
\hline General practitioner, per visit & 19.1 \\
\hline \multicolumn{2}{|l|}{ Hospital costs } \\
\hline Physiotherapist creating rehabilitation plan & 21.3 \\
\hline \multicolumn{2}{|l|}{ Indirect nonhealthcare costs } \\
\hline Absenteeism from work, per day & 216 \\
\hline
\end{tabular}


TABLE 3. Outcome parameters

\begin{tabular}{|c|c|c|c|c|}
\hline Parameter & REHAB & HOME & $\Delta$ Mean & p Value \\
\hline \multicolumn{5}{|l|}{$E Q-5 D(S D)$} \\
\hline Preop, mean $(n=72 ; 73)$ & $0.511(0.26)$ & $0.493(0.26)$ & 0.018 & 0.68 \\
\hline 1-mo baseline $(n=71 ; 71)$ & $0.757(0.17)$ & $0.753(0.14)$ & 0.004 & 0.88 \\
\hline \multicolumn{5}{|l|}{ Mean improvements } \\
\hline $3 \operatorname{mos}(n=41 ; 46)$ & $0.050(0.13)$ & $0.027(0.12)$ & 0.023 & 0.38 \\
\hline $6 \operatorname{mos}(n=47 ; 40)$ & $0.043(0.16)$ & $0.018(0.10)$ & 0.025 & 0.40 \\
\hline $12 \operatorname{mos}(n=44 ; 45)$ & $0.068(0.19)$ & $0.054(0.18)$ & 0.014 & 0.73 \\
\hline $24 \operatorname{mos}(n=47 ; 41)$ & $0.057(0.19)$ & $0.039(0.17)$ & 0.018 & 0.65 \\
\hline QALY complete data $(n=44 ; 46)$ & $0.757(0.13)$ & $0.751(0.19)$ & 0.006 & 0.87 \\
\hline QALY imputed data $(n=62 ; 64)$ & $0.755(0.11)$ & $0.734(0.16)$ & 0.021 & 0.39 \\
\hline \multicolumn{5}{|l|}{ ODI (SD) } \\
\hline Preop $(n=71 ; 71)$ & $45.3(17.9)$ & $43.3(14.7)$ & 1.88 & 0.49 \\
\hline 1-mo baseline $(n=67 ; 71)$ & $18.9(15.9)$ & $19.9(14.2)$ & 1.02 & 0.69 \\
\hline \multicolumn{5}{|l|}{ Mean improvements } \\
\hline $3 \operatorname{mos}(n=40 ; 46)$ & $-4.75(8.6)$ & $-3.30(9.86)$ & 1.44 & 0.47 \\
\hline $6 \operatorname{mos}(n=44 ; 39)$ & $-3.06(13.7)$ & $-2.51(10.37)$ & 0.55 & 0.84 \\
\hline $12 \operatorname{mos}(n=39 ; 44)$ & $-4.95(9.0)$ & $-5.66(9.12)$ & 0.71 & 0.72 \\
\hline $24 \operatorname{mos}(n=40 ; 42)$ & $-6.65(9.4)$ & $-3.09(9.11)$ & 3.55 & 0.09 \\
\hline Mean postop sick leave, days (SD) & $110.6(137.6)$ & $98.7(110.5)$ & 11.9 & 0.60 \\
\hline
\end{tabular}

The parenthetical numbers in the Parameter column indicate the number of patients in the REHAB and HOME groups, respectively, who replied to the questionnaires at each follow-up point.

summary of outcome improvements during the follow-up period.

The primary cost-effectiveness analysis showed an additional QALY gain of 0.021 (-0.07:0.03) at an incremental cost of $€ 211.8$ (range $€ 107.9-€ 316.9$ ) for the REHAB group compared to the HOME group. The ICER was thereby calculated to be $€ 10,085.7$ (Fig. 2). The astreated sensitivity analysis showed that the REHAB group was dominated by the HOME group; in other words, the HOME group had greater QALY improvements and in-

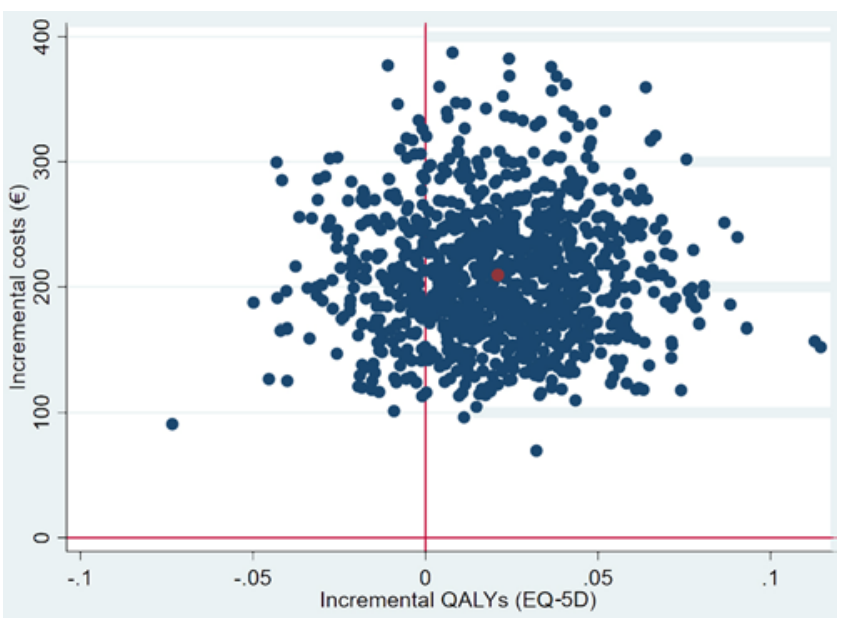

FIG. 2. Graph illustrating the ICERs after bootstrapping with 1000 replications. Figure is available in color online only. curred lower costs than the REHAB group. ICERs from additional sensitivity analyses are presented in Table 4.

The cost-effectiveness acceptability curve showed a probability of 0.71 for referral to municipal rehabilitation to be cost-effective at a threshold value of $€ 30,000$. Inclusion of the as-treated and per-protocol data decreased the probability to 0.15 and 0.37 , respectively (Fig. 3).

\section{Discussion}

This cost-effectiveness analysis suggests that routine

TABLE 4. Difference in costs, QALYs, and ICERs in REHAB patients compared to HOME patients (complete data)

\begin{tabular}{cccc}
\hline & $\begin{array}{c}\text { Incremental } \\
\text { Cost }(€)\end{array}$ & $\begin{array}{c}\text { Incremental } \\
\text { QALY }\end{array}$ & ICER $(\Delta € / \Delta Q A L Y)$ \\
\hline Main & 211.8 & 0.021 & $10,085.7$ \\
\hline Sensitivity & & & \\
\hline $1^{*}$ & 211.8 & 0.018 & $11,766.7$ \\
\hline $2 \dagger$ & 216.2 & -0.015 & Dominance \\
\hline $3 \ddagger$ & 1855.3 & 0.021 & $88,347.6$ \\
\hline $4 \S$ & 296.2 & 0.002 & 148,100 \\
\hline $5 \uparrow$ & 287.9 & -0.015 & Dominance \\
\hline
\end{tabular}

* United Kingdom-weighted EQ-5D.

$\dagger$ 24-month EQ-5D scores included.

$\ddagger$ Absenteeism costs included.

$\S$ Per-protocol data analyzed.

ๆ As-treated data analyzed. 


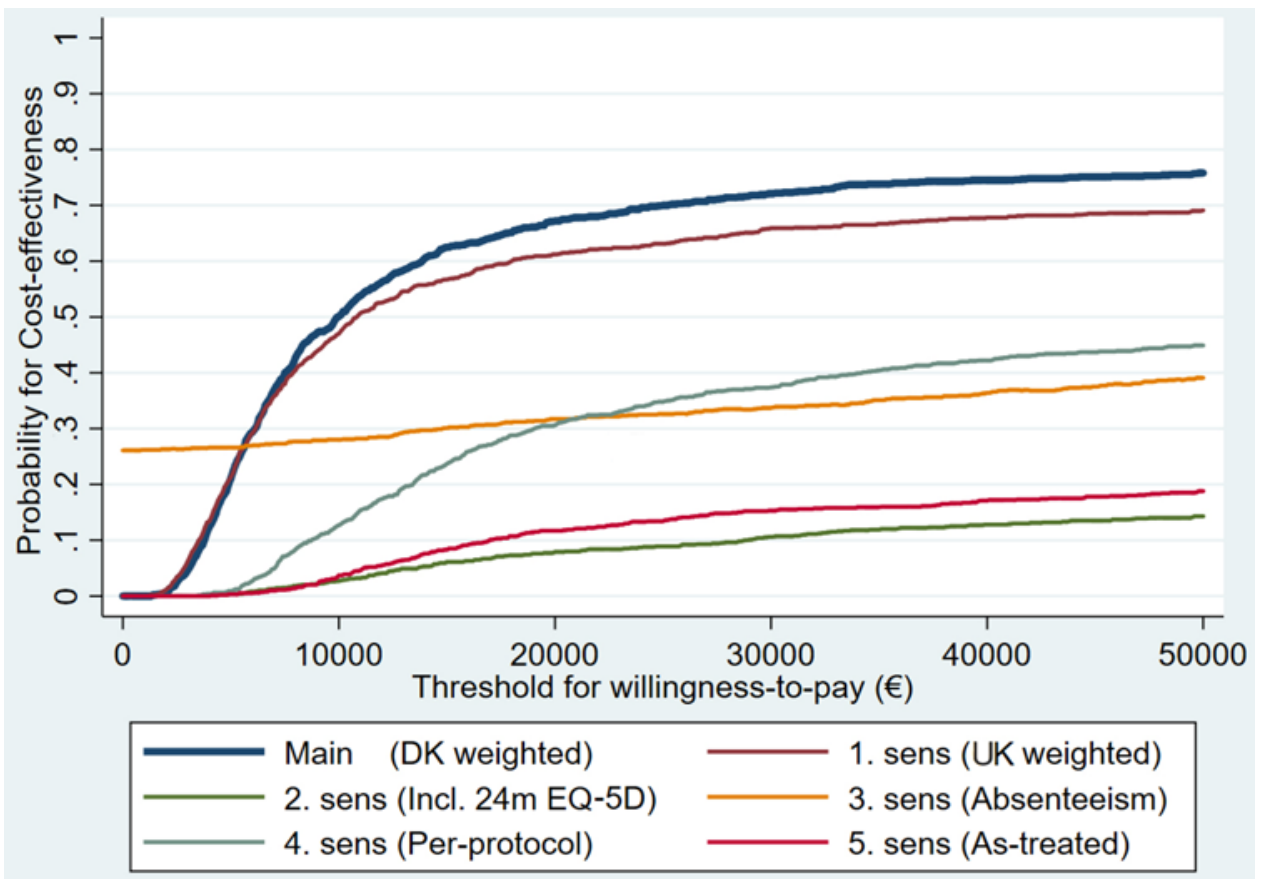

FIG. 3. Graph illustrating the cost-effectiveness acceptability curves on main and sensitivity analyses. DK = Danish-weighted EQ5D scores; Incl. = including; sens = sensitivity analysis; UK = United Kingdom-weighted EQ-5D scores; $24 \mathrm{~m}=24-\mathrm{month} E Q-5 D$ scores. Figure is available in color online only.

referral for municipal rehabilitation after surgery for LDH is not cost-effective compared to no referral. Figure 3 reveals that rehabilitation has a $71 \%$ chance of being costeffective with a societal willingness to pay of $€ 30,000 /$ QALY. In the sensitivity analyses, ICERs of the REHAB group increased or were dominated by the HOME group. These results are well in line with those reported in the Morris et al. study, ${ }^{11}$ which found a probability of 0.52 that postoperative rehabilitation was cost-effective at a threshold value of $€ 58,000 / \mathrm{QALY}$, and with those reported in the Oosterhuis et al. study, ${ }^{13}$ which found a 0.75 probability of cost-effectiveness at a threshold value of $€ 32,000 /$ QALY.

During the follow-up period, the REHAB group had slightly better scores on the EQ-5D compared to the HOME group, but none of these differences reached the MCID and none were of statistical significance. The HOME group had a slightly poorer mean EQ-5D score at baseline than the REHAB group.

At the 1-year follow-up, we had complete EQ-5D scores for $70.6 \%$ of the sample. This response rate is lower than anticipated and required application of imputations for the cost-effectiveness analyses. This is a potential bias, but a previous study ${ }^{5}$ using data from our spine database (DaneSpine) investigated differences between the responders and nonresponders. Højmark and colleagues found no differences in patient satisfaction, disability, or pain between the groups of respondents. ${ }^{5}$ The EQ-5D scores, however, were significantly higher in the group of nonresponders, and this could potentially underestimate the change in EQ$5 \mathrm{D}$ scores in the current study, but because of our randomization, we expect that the potential underestimation from the nonresponders occurred equally in both groups.
A previous study that reported on the same cohort ${ }^{16}$ as the present study did not find any statistically significant differences in duration of sick leave between the rehabilitation groups. For this reason, the costs of absenteeism were not included in the main analysis of cost-effectiveness. However, we included the cost of absenteeism in the third sensitivity analysis because it was clear that the indirect costs of absenteeism were the largest contributors to the total cost in both groups. However, the probability of referral to municipal postoperative rehabilitation being cost-effective was not improved due to this, supporting the conclusion that referral to postoperative rehabilitation is not cost-effective in comparison with no referral.

One of the strengths of this study is its design with well-executed randomization and blinding of the primary researcher during the study. In contrast to the study by Oosterhuis et al., ${ }^{13}$ we evaluated cost-effectiveness using a time perspective from 3 to 24 months, whereas Oosterhuis et al. evaluated costs and effect after 26 weeks. An additional strength is that our study was conducted as a single-center study, ensuring uniform inclusion and homogeneous treatments of the patients at the hospital. However, there were uncertainties, and one was the assumption related to this kind of economic analysis. Cost estimations were partly based on assumptions, with a potential risk of either over- or underestimating the costs. However, we used publicly available unit costs in the calculations and attempted to include all relevant costs for rehabilitation. This includes training facilities, equipment, and ongoing maintenance. We collected patient diaries of external treatments and visits to their general practitioners during the initial 3 months, but for various reasons, the followup rate of these diaries was poor, with only $40 \%$ in both 
groups, even though a higher percentage of patients ( $>$ $40 \%$ ) completed the additional 3-month questionnaires.

Another limitation to this study was the fact that the primary study of this cohort evaluated other outcome parameters and their association with postoperative rehabilitation, which means that the data collection was powered to detect a difference in the ODI score and not the EQ-5D score.

The rehabilitation programs in this study were not standardized for the REHAB group and this could be considered a limitation. However, we published a study ${ }^{14}$ which found that rehabilitation programs are overall comparable in terms of the type, duration, and postoperative outcomes seen among the municipalities used in this study. The aim of the present study was not to compare one type of rehabilitation program to another, but instead to evaluate the effects of prescribing postoperative rehabilitation for all LDH patients as part of our daily practice.

This study is important from a societal perspective due to the increasing public health expenditures in Denmark and the fact that the evidence for a positive effect of postoperative rehabilitation is sparse. In publicly provided healthcare systems with free access to healthcare, as in Denmark, it is especially important for politicians and healthcare professionals to reflect on efficiency when using the limited public health resources and when deciding whether all patients should be offered rehabilitation or not. Our study indicates that patient outcome is not improved by routinely referring patients to municipal rehabilitation after surgery, and the cost per QALY gained is too high to be considered as cost-effective. Based on our study, we recommend that future studies use a selective approach before referring patients to municipal rehabilitation. By an improved and more targeted patient selection, it is likely that there may be positive effects of postoperative rehabilitation in patients recovering from LDH surgery.

\section{Conclusions}

Routine referral for municipal physical rehabilitation in patients recovering from LDH surgery was not cost-effective compared to no referral.

\section{Acknowledgments}

Funding was received from the Research Council of Southern Denmark, Research Council of Lillebaelt Hospital, and the Orthopedic Department, Lillebaelt Hospital.

\section{References}

1. Andersen M, Nielsen M, Bech-Azeddine R, Helmig og Søren Eiskjær P: DaneSpine Annual Report 2017 (http://www. drksdanespine.dk/wm420129) [Accessed November 20, 2019]

2. Copay AG, Glassman SD, Subach BR, Berven S, Schuler TC, Carreon LY: Minimum clinically important difference in lumbar spine surgery patients: a choice of methods using the Oswestry Disability Index, Medical Outcomes Study questionnaire Short Form 36, and pain scales. Spine J 8:968-974, 2008

3. Fairbank JCT, Pynsent PB: The Oswestry Disability Index. Spine (Phila Pa 1976) 25:2940-2952, 2000

4. Gadjradj PS, Arts MP, van Tulder MW, Rietdijk WJR, Peul WC, Harhangi BS: Management of symptomatic lumbar disk herniation: an international perspective. Spine (Phila Pa 1976) 42:1826-1834, 2017

5. Højmark K, Støttrup C, Carreon L, Andersen MO: Patientreported outcome measures unbiased by loss of follow-up. Single-center study based on DaneSpine, the Danish spine surgery registry. Eur Spine J 25:282-286, 2016

6. Johnsen LG, Hellum C, Nygaard ØP, Storheim K, Brox JI, Rossvoll I, et al: Comparison of the SF6D, the EQ5D, and the Oswestry Disability Index in patients with chronic low back pain and degenerative disc disease. BMC Musculoskelet Disord 14:148, 2013

7. Laegeforeningen: Honorarer og takster. Praktiserende Lægers Organisation (https://www.laeger.dk/PLO-honorarer-ogtakster) [Accessed November 20, 2019]

8. Luijsterburg PAJ, Verhagen AP, Ostelo RWJG, van Os TAG, Peul WC, Koes BW: Effectiveness of conservative treatments for the lumbosacral radicular syndrome: a systematic review. Eur Spine J 16:881-899, 2007

9. McCabe C, Claxton K, Culyer AJ: The NICE cost-effectiveness threshold: what it is and what that means. Pharmacoeconomics 26:733-744, 2008

10. Moher D, Hopewell S, Schulz KF, Montori V, Gøtzsche PC, Devereaux PJ, et al: CONSORT 2010 explanation and elaboration: updated guidelines for reporting parallel group randomised trials. Int J Surg 10:28-55, 2012

11. Morris S, Morris TP, McGregor AH, Doré CJ, Jamrozik K: Function after spinal treatment, exercise, and rehabilitation: cost-effectiveness analysis based on a randomized controlled trial. Spine (Phila Pa 1976) 36:1807-1814, 2011

12. Oosterhuis T, Costa LOP, Maher CG, de Vet HCW, van Tulder MW, Ostelo RWJG: Rehabilitation after lumbar disc surgery. Cochrane Database Syst Rev 3:CD003007, 2014

13. Oosterhuis T, Ostelo RW, van Dongen JM, Peul WC, de Boer MR, Bosmans JE, et al: Early rehabilitation after lumbar disc surgery is not effective or cost-effective compared to no referral: a randomised trial and economic evaluation. J Physiother 63:144-153, 2017

14. Paulsen RT, Bergholdt E, Carreon L, Rousing R, Hansen KH, Andersen M: No differences in post-operative rehabilitation across municipalities in patients with lumbar disc herniation. Dan Med J 62:A5104, 2015

15. Paulsen RT, Carreon LY, Andersen MØ: Patient reported outcomes after surgery for lumbar disk herniation, a randomized controlled trial comparing the effects of referral to municipal physical rehabilitation versus no referral. Spine (Phila Pa 1976) 45:3-9, 2020

16. Paulsen RT, Rasmussen J, Carreon LY, Andersen MØ: Return to work after surgery for lumbar disc herniation, secondary analyses from a randomized controlled trial comparing supervised rehabilitation versus home exercises. Spine J 20:41-47, 2020

17. Sørensen J, Davidsen M, Gudex C, Pedersen KM, BrønnumHansen H: Danish EQ-5D population norms. Scand J Public Health 37:467-474, 2009

18. Stafford MA, Peng P, Hill DA: Sciatica: a review of history, epidemiology, pathogenesis, and the role of epidural steroid injection in management. Br J Anaesth 99:461-473, 2007

\section{Disclosures}

Dr. Carreon reports that researchers and PhD students affiliated with the Spine Surgery and Research department at the Spine Center of Southern Denmark have received financial support from Sygehus Lillebælt Forskningsråd, Sygehus Lillebælt Udviklingsråd, SDU faculty scholarship, Gangstedsfonden, Gigtforeningen, Region Syddanmarks ph.d. pulje, Region Syddanmarks forskningspulje, Region Sjælland og Region Syddanmarks fælles forskningspulje, Det Frie Forskningsråd, A.P. Møller Fonden for Lægevidenskabens Fremme, Inger Goldmanns Fond, IMK Almene Fond, 
Aase og Ejnar Danielsens Fond, Overlæge Jørgen Werner Schous og hustru, Else-Marie Schou, født Wonge's fond, Cerapedics, Fonden til fremme af kiropraktisk forskning og postgraduat uddannelse, Eli Lilly, Kroghs Legat, Ortotech, Guildal Fondet, and Janssen-Cilag A/S.

Dr. Carreon is an employee of Norton Healthcare. She is on the editorial advisory board of Spine Deformity, The Spine Journal, and Spine. She is a member of the IRB at the University of Louisville, and she is on the research committee at SRS.

\section{Author Contributions}

Conception and design: Paulsen, Carreon, Andersen. Acquisition of data: Paulsen, Andersen. Analysis and interpretation of data: Paulsen, Sørensen, Carreon. Drafting the article: Paulsen. Critically revising the article: all authors. Reviewed submitted version of manuscript: Sørensen, Carreon, Andersen. Statistical analysis: Paulsen, Sørensen, Carreon. Study supervision: Carreon, Andersen.

\section{Correspondence}

Rune Tendal Paulsen: Spine Centre of Southern Denmark, Lillebaelt Hospital, Middelfart, Denmark.rune.tendal.paulsen@ rsyd.dk. 